\title{
Magnetohydrodynamic Boundary Layer Flow of Non-Newtonian Fluid and Combined Heat and Mass Transfer about an Inclined Stretching Sheet
}

\author{
Md. Shah Alam¹, Md. Rashedul Islam², Mohammad Ali1', Md. Abdul Alim³, \\ Md. Mahmud Alam4 \\ ${ }^{1}$ Department of Mathematics, Chittagong University of Engineering and Technology (CUET), Chittagong, \\ Bangladesh \\ ${ }^{2}$ Department of Computer Science and Engineering, International Islamic University Chittagong (IIUC), \\ Chittagong, Bangladesh \\ ${ }^{3}$ Department of Mathematics, Bangladesh University of Engineering and Technology (BUET), Dhaka, \\ Bangladesh \\ ${ }^{4}$ Mathematics Discipline, Khulna University (KU), Khulna, Bangladesh \\ Email: shahalammaths@gmail.com, rashed maths@cse.iiuc.ac.bd, ${ }^{*}$ ali.mehidi93@gmail.com, \\ maalim@math.buet.ac.bd
}

Received 14 May 2015; accepted 20 June 2015; published 23 June 2015

Copyright (C) 2015 by authors and Scientific Research Publishing Inc.

This work is licensed under the Creative Commons Attribution International License (CC BY). http://creativecommons.org/licenses/by/4.0/

(c) (7) Open Access

\section{Abstract}

The steady magneto hydrodynamic (MHD) boundary layer flow and combined heat and mass transfer of a non-Newtonian fluid over an inclined stretching sheet have been investigated in the present analysis. The effects of the flow parameters on the velocity, temperature, species concentration, local skin friction, local Nusselt number, and Sherwood number are computed, discussed and have been graphically represented in figures and tables for various values of different parameters. The numerical results are carried out for several values of the combined effects of magnetic parameter $M$, stretching parameter $\lambda$, Prandtl number $P r$, Eckert number $E c$, Schmidt number $S c$, Soret number $S_{0}$, slip parameter $A$ and Casson parameter $n$ on velocity, temperature and concentration profiles and also the skin-friction coefficient $f^{\prime \prime}(0)$, local Nusselt number $-\theta^{\prime}(0)$ and local Sherwood number $-\varphi^{\prime}(0)$ are discussed and presented in tabular form. The results pertaining to the present study indicate that the velocity profiles decrease as the increase of magnetic field parameter, but reverse trend arises for the effect of Casson parameter and stretching ratio parameter for both Newtonian and non-Newtonian fluids. The temperature profiles increase

\footnotetext{
"Corresponding author.
}

How to cite this paper: Alam, Md.S., Islam, Md.R., Ali, M., Alim, Md.A. and Alam, Md.M. (2015) Magnetohydrodynamic Boundary Layer Flow of Non-Newtonian Fluid and Combined Heat and Mass Transfer about an Inclined Stretching Sheet. Open Journal of Applied Sciences, 5, 279-294. http://dx.doi.org/10.4236/ojapps.2015.56029 
for the effect of magnetic parameter, Prandtl number and Eckert number in case of Newtonian and non-Newtonian fluids. The concentration profile increases for the effect of Soret number while concentration profile decreases for the increasing values of Schmidt number, magnetic parameter, Prandtl number and Eckert number for both Newtonian and non-Newtonian fluids. By considering the cooling plate the numerical results for the skin-friction coefficient $f^{\prime \prime}(0)$, local Nusselt number $-\theta^{\prime}(0)$ and local Sherwood number $-\varphi^{\prime}(0)$ are presented in Tables 1-3.

\section{Keywords}

\section{MHD, Casson Fluid, Stretching Sheet, Angle of Inclination}

\section{Introduction}

The non-Newtonian fluid flow is important for their numerous engineering applications. The various types of non-Newtonian fluids are nano fluid, Casson fluid, viscoelastic fluid, couple stress fluid, micro polar fluid, power-law flow, etc. These include pseudo plastic, dilatant, blood, foodstuff, slurries, cosmetics \& toiletries and paints. Heat transfer in boundary layer over a stretching sheet has important applications in extrusion of plastic sheets, polymer, spinning of fibers, cooling of elastic sheets, etc. The quality of final product depends on the rate of heat transfer, and as a result the cooling procedure has to be controlled effectively. The MHD boundary layer flow of heat and mass transfer problems about an stretching sheet have become in view of its significant applications in industrial manufacturing processes such as plasma studies, petroleum industries, magneto-hydrodynamics power generator, cooling of nuclear reactors, boundary layer control in aerodynamics, glass fiber production and paper production. In recent years, due to the growing applications of non-Newtonian fluids, various researchers have done different works in this field. Astarita and Marrucci [1] and Bhome [2] have studied the behavior of non-Newtonian fluids in case of steady and unsteady flow situations. At first, Schowalter [3] [4] formulated the boundary layer flow of a Non-Newtonian fluid and also established the existence conditions of a similarity solution. A similarity solution has been done by Acrivos et al. [5] for a power-law fluid flowing along a vertical flat plate. Heat transfer of a non-Newtonian power-law fluid over a stretching surface in the presence of radiation and slip condition at the surface was investigated by Mostafa [6]. Khan and Pop [7] have studied the fundamental work on the boundary layer flow of nano fluid over a stretching sheet. Rana and Bhargava [8] performed the numerical study of heat transfer characteristic in the mixed convection flow of a nano fluid along a vertical plate in presence of heat source/sink. Rama and Goyal [9] have studied non-Newtonian nano fluid flow over a permeable sheet with heat generation and velocity slip in presence of magnetic field. Noghrehabadi et al. [10] studied the partial slip eeffect on the flow and heat transfer of nano fluids over a stretching sheet.

In this regard the aim of this work is to investigate the steady boundary layer flow and combined heat and mass transfer of a non-Newtonian fluid over an inclined stretching sheet in presence of uniform magnetic field. The numerical results are carried out for several values of the combined effects of magnetic parameter $M$, stretching parameter $\lambda$, Prandtl number $P r$, Eckert number $E c$, Schmidt number $S c$, Soret number $S_{0}$, slip parameter $A$ and Casson parameter $n$ on velocity, temperature and concentration profiles and also the skin-friction coefficient $f^{\prime \prime}(0)$, local Nusselt number $-\theta^{\prime}(0)$ and local Sherwood number $-\varphi^{\prime}(0)$ are discussed by considering cooling plate.

\section{Mathematical Formulation of the Problem and Similarity Analysis}

Let us consider a two dimensional steady laminar viscous incompressible MHD flow of an electrically conducting fluid along an inclined stretching sheet with an acute angle $(\alpha), X$-direction is taken along the leading edge of the inclined stretching sheet and $Y$ is normal to it and extends parallel to $X$-axis. A magnetic field of strength $B_{0}$ is introduced to the normal to the direction to the flow. The uniform plate temperature $T_{w}\left(>T_{\infty}\right)$, where $T_{\infty}$ is the temperature of the fluid far away from the plate. Let $u$ and $v$ be the velocity components along the $x$ and $y$ axis respectively in the boundary layer region. Under the above assumptions and usual boundary layer approximation, the dimensional governing equations of continuity, momentum, concentration and energy under the influence of 
externally imposed magnetic field [11] are:

Equation of continuity:

$$
\frac{\partial u}{\partial x}+\frac{\partial v}{\partial y}=0
$$

Momentum equation:

$$
u \frac{\partial u}{\partial x}+v \frac{\partial u}{\partial y}=-\frac{1}{\rho} \frac{\partial p}{\partial x}+v \frac{\partial}{\partial y}\left[\left|\frac{\partial u}{\partial y}\right|^{n-1} \frac{\partial u}{\partial y}\right]+g \beta\left(T-T_{\infty}\right) \cos \alpha+g \beta^{*}\left(C-C_{\infty}\right) \cos \alpha-\frac{\sigma B_{0}^{2} u}{\rho}
$$

Energy equation:

$$
u \frac{\partial T}{\partial x}+v \frac{\partial T}{\partial y}=\frac{\kappa}{\rho c_{p}} \frac{\partial^{2} T}{\partial y^{2}}+\frac{\mu}{\rho c_{p}}\left|\frac{\partial u}{\partial y}\right|^{n+1}
$$

Concentration equation:

$$
u \frac{\partial C}{\partial x}+v \frac{\partial C}{\partial y}=D_{m} \frac{\partial^{2} C}{\partial y^{2}}+\frac{D_{m} K_{T}}{T_{m}} \frac{\partial^{2} T}{\partial y^{2}}
$$

Using free stream velocity

$$
u=U(x)=b x
$$

The Equation (2) can be written as

$$
u \frac{\partial u}{\partial x}+v \frac{\partial u}{\partial y}=U \frac{\partial U}{\partial x}+v \frac{\partial}{\partial y}\left[\left|\frac{\partial u}{\partial y}\right|^{n-1} \frac{\partial u}{\partial y}\right]+g \beta\left(T-T_{\infty}\right) \cos \alpha+g \beta^{*}\left(C-C_{\infty}\right) \cos \alpha-\frac{\sigma B_{0}^{2}(u-U)}{\rho}
$$

where $u$ and $v$ are the velocity components along $x$ and $y$ directions, $T, T_{w}$ and $T_{\infty}$ are the fluid temperature, the stretching sheet temperature and the free stream temperature respectively while $C, C_{w}$ and $C_{\infty}$ are the corresponding concentrations, $\kappa$ is the variable thermal conductivity of the fluid, $c_{p}$ specific heat with constant pressure, $\alpha$ is the angle of inclination, $\mu$ is the coefficient of viscosity, $v$ is the kinematic viscosity, $\sigma$ is the electrical conductivity, $\rho$ is the fluid density, $\beta$ is the thermal expansion coefficient, $\beta^{*}$ is the concentration expansion coefficient, $B_{0}$ is the magnetic field intensity, $U$ is the free steam velocity, $g$ is the acceleration due to gravity, $D_{m}$ is the coefficient of mass diffusivity, $T_{m}$ is the mean fluid temperature, $K_{T}$ is the thermal diffusion ratio respectively and $n$ is known as non-dimensional power-law index (Casson parameter) and it is an important index to sub-classified fluids like pseudo plastic fluids $(n<1)$ and dilatant fluids $(n>1)$. Also for $n=1$, the fluid is simply the Newtonian fluid. The deviation of $\mathrm{n}$ from unity indicates that the degree of deviation from Newtonian behavior [12].

The above equations are subject to the following boundary conditions:

$$
\begin{aligned}
& u=a x, v=0, T=T_{w}, C=C_{w} \text { at } y=0 \\
& u \rightarrow U=b x, T \rightarrow T_{\infty}, C \rightarrow C_{\infty} \text { as } y \rightarrow \infty
\end{aligned}
$$

To convert the governing equations into a set of similarity equations, we introduce the following similarity transformation:

$$
\psi=x \sqrt{a v} f(\eta), \eta=y \sqrt{\frac{a}{v}}, \theta(\eta)=\frac{T-T_{\infty}}{T_{w}-T_{\infty}}, \varphi(\eta)=\frac{C-C_{\infty}}{C_{w}-C_{\infty}},
$$

The steam function $\psi(x, y)$ as defined by

$$
u=\frac{\partial \psi}{\partial y} \text { and } v=-\frac{\partial \psi}{\partial x}
$$

From the above transformations, the non-dimensional, nonlinear and coupled ordinary differential equations 
are obtained

$$
\begin{gathered}
A n\left|f^{\prime \prime}\right|^{n-1} f^{\prime \prime \prime}+f f^{\prime \prime}-f^{\prime 2}-M\left(f^{\prime}-\lambda\right)+G r \theta \cos \alpha+G m \varphi \cos \alpha+\lambda^{2}=0 \\
\theta^{\prime \prime}+\operatorname{PrEc}\left|f^{\prime \prime}\right|^{n+1}+\operatorname{Pr} f \theta^{\prime}=0 \\
\varphi^{\prime \prime}+S c f \varphi^{\prime}-S_{0} \operatorname{Pr} E c\left|f^{\prime \prime}\right|^{n+1}-S_{0} \operatorname{Pr} f \theta^{\prime}=0
\end{gathered}
$$

The transform boundary conditions:

$$
\begin{aligned}
& f=0, f^{\prime}=1, \theta=\varphi=1 \text { at } \eta=0, \\
& f^{\prime}=\lambda, \theta=\varphi=0 \text { as } \eta \rightarrow \infty
\end{aligned}
$$

where $f^{\prime}, \theta$ and $\varphi$ are the dimensionless velocity, temperature and concentration respectively, $\eta$ is the similarity variable, $A$ is the slip parameter, the prime denotes differentiation with respect to $\eta$. Also

$$
\begin{aligned}
& M=\frac{\sigma B_{0}^{2}}{\rho a}, \lambda=\frac{b}{a}, G r=\frac{g \beta\left(T_{w}-T_{\infty}\right)}{a x}, G m=\frac{g \beta^{*}\left(C_{w}-C_{\infty}\right)}{a x}, \operatorname{Pr}=\frac{\mu c_{p}}{\kappa}, S c=\frac{v}{D_{m}}, \\
& E C=\frac{a^{\frac{3 n+1}{2}} x^{n}}{\left(T_{w}-T_{\infty}\right)}, A=\frac{x^{n} a^{\frac{3(n-1)}{2}}}{v^{\frac{n-1}{2}}} \text { and } S_{0}=\frac{K_{T}\left(T_{w}-T_{\infty}\right)}{T_{m}\left(C_{w}-C_{\infty}\right)}
\end{aligned}
$$

are the magnetic parameter, stretching ratio, Grashof number, modified Grashof number, Prandtl number, Schmidt number, Eckert number, slip parameter and Soret number respectively. The important physical quantities of this problem are skin friction coefficient $C_{f}$, the local Nusselt number $N u$ and the local Sherwood number $S h$ which are proportional to rate of velocity, rate of temperature and rate of mass transfer respectively.

\section{Methodology}

The governing partial differential equations are transformed into ordinary differential equations by using similarity transformation and stretching variable. The flow is considered under the influence of a stretching velocity and a uniform magnetic field. The governing thermal boundary layer Equation (3), concentration boundary layer Equation (4) and momentum boundary layer Equation (5) with the boundary conditions Equation (6) are transformed into a system of ordinary differential equations by the suitable local similarity transformations which are then solved numerically by using Runge-Kutta fourth-fifth order method along with shooting iteration technique. The higher order nonlinear differential equations are converted into simultaneous linear differential equations of first order and they are further transformed into initial value problem applying the shooting technique. First of all, the coupled ordinary differential Equations (7)-(9) are third order in $f$ and second order in $\theta$ and $\varphi$ which have been reduced to a system of seven simultaneous ordinary differential equations for seven unknowns. For the purpose of numerically solve this system of equations using Runge-Kutta method, the solution requires seven initial conditions but two initial conditions in $f$, one initial condition in each of $\theta$ and $\varphi$ are known. However, the values of $f^{\prime}, \theta$ and $\varphi$ are known at $\eta \rightarrow \infty$. These end conditions are utilized to produce unknown initial conditions at $\eta \rightarrow \infty$ by using shooting technique. The most important step of this scheme is to choose the appropriate finite value of $\eta_{\infty}$.

Thus to estimate the value of $\eta_{\infty}$, we start with some initial guess value and solve the boundary value problem consisting of Equations (7)-(9) to obtain $f^{\prime \prime}(0), \theta^{\prime}(0)$ and $\varphi^{\prime}(0)$. The solution process is repeated with another larger value of $\eta_{\infty}$ until two successive values of $f^{\prime \prime}(0), \theta^{\prime}(0)$ and $\varphi^{\prime}(0)$ differ only after desired significant digit. The last value $\eta_{\infty}$ is taken as the finite value of the limit for the particular set of physical parameters for determining velocity, temperature and concentration, respectively, are $f(\eta), \theta(\eta)$ and $\varphi(\eta)$ in the boundary layer. After getting all the initial conditions we solve this system of simultaneous equations using fourth order Runge-Kutta integration scheme. The effects of the flow parameters on the velocity, temperature, species concentration, shearing stress, rate of heat transfer, and rate of concentration are computed, discussed and have been graphically represented in figures and tables for various value of different parameters. Now defining new variables by the equations $y_{1}=f, y_{2}=f^{\prime}, y_{3}=f^{\prime \prime}, y_{4}=\theta, y_{5}=\theta^{\prime}, y_{6}=\varphi, y_{7}=\varphi^{\prime}$. The higher order differential Equations (7)-(9) and boundary conditions Equation (10) may be transformed to seven equivalent first order differential equations and boundary conditions respectively are given below: 


$$
\begin{aligned}
& \mathrm{d} y_{1}=y_{2}, \mathrm{~d} y_{2}=y_{3}, \mathrm{~d} y_{3}=\frac{y_{3}^{1-n}}{A n}\left[-y_{1} y_{3}+y_{2}^{2}+M y_{2}+\lambda M-\lambda^{2}-G r \cos \alpha y_{4}-G m \cos \alpha y_{6}\right], \\
& \mathrm{d} y_{4}=y_{5}, \mathrm{~d} y_{5}=-\operatorname{PrEc} y_{3}^{n+1}-\operatorname{Pr} y_{1} y_{5}, \mathrm{~d} y_{6}=y_{7}, \mathrm{~d} y_{7}=-S c y_{1} y_{7}+S_{0} \operatorname{PrEc} y_{3}^{n+1}+S_{0} \operatorname{Pr}_{1} y_{5}
\end{aligned}
$$

And the boundary conditions are

$$
y_{1}=0, y_{2}=1, y_{4}=1, y_{6}=1 \text { at } \eta=0 \text {, and } y_{2}=\lambda, y_{4}=0, y_{6}=0 \text { as } \eta \rightarrow \infty
$$

\section{Results and Discussion}

Numerical calculation for distribution of the velocity, temperature and concentration profiles across the boundary layer for different values of the parameters are carried out in presence of cooling of the plate $(G r>0)$. For the purpose of our simulation we have chosen $\lambda=0.85, M=0.3, n=0.9, n=1.0, n=1.9, A=0.5, G r=2.0, G m$ $=2.0, S_{C}=0.22, \operatorname{Pr}=1.0, E_{C}=1.0, S_{0}=0.4$, and $\alpha=30^{\circ}$ while the parameters are varied over range as shown in the figures. Figures 1-26 depict the effect of different entering parameters for (a) Pseudo plastic fluid $(n<1)$ (b) Dilatants fluid $(n>1)$ (c) Newtonian fluid for $(n=1)$. From Figures 1-3 it is observed that the velocity profile decreases for both Newtonian and non-Newtonian fluids with increase in magnetic parameter, $M$ because the presence of $M$ in an electrically conducting fluid introduces a force like Lorentz force which acts against the flow if the magnetic field is applied in the normal direction as in the present problem. As a result velocity profile is decreased. Figures 4-6 displayed the effect of stretching parameter on velocity profile. From these figures it is shown that the velocity is increased for both Newtonian and non-Newtonian fluids. The effects of Casson parameter are shown in Figure 7 and Figure 8. It is observed that the velocity is decreased for Dilatant fluids but increased in case of Pseudo plastic fluids. Therefore, it is observed that the momentum boundary layer thickness for Pseudo plastic fluid $(n<1)$ is greater than that of Dilatants fluid $(n>1)$. It happens because of plasticity of Casson fluid. The plasticity of the fluid increases while Casson parameter decreases, which causes the increment in velocity boundary layer thickness. From Figures 9-11 it is observed that the temperature profile increases for the increasing values of magnetic parameter both the case of Newtonian and non-Newtonian fluids which means that the applied magnetic field in an electrical conducting fluid is manifested as thermal energy. This heats conducting Newtonian and non-Newtonian fluids and hence increases the temperature. Besides the fluid velocity is decreased for magnetic parameter which leads to a decrease in heat convection and mass diffusion, and thus fluid temperature and species concentration in fluid increases. From Figures 12-14 it is observed that the temperature decreases up to $\eta<1$ and increase $1 \leq \eta<5$ and then decreases for the increasing values of Prandtl number in case of Newtonian and non-Newtonian fluids. Since Prandtl number is a property of fluids that is a fluid with small Prandtl number, in general, has high thermal diffusivity. Due to this property the fluid temperature is higher for a lower Prandtl number fluid and vice-versa. The increase in fluid temperature in turn increases the buoyancy force and so the fluid velocity increases. The increase in fluid velocity leads to better species diffusion; therefore, the species concentration decreases in the fluid, which is seen in Figure 26. Again, Figures 15-17 depict the temperature profile for increasing values of Eckert number. From these figures it is observed that the temperature profile increase for the effect of Eckert number because heat energy is stored within the fluid due to the frictional heating as a result enhanced the temperature. From the Figure 18-20 it is seen that the concentration profile is increased for increasing values of Soret number in case of both the Newtonian and non-Newtonian fluids. A similar kind of interplay as above for $P r$, occurs for Schmidt number $S c$ and is seen in Figures 21-23. Schmidt number is a property of fluids that is a smaller value of $S c$ means better diffusion of species in fluid. Hence, for a small Schmidt number the species concentration in the fluid is higher and vice-versa for both Newtonian and non-Newtonian fluids.

Similar result has been found for the increasing effect of magnetic parameter and Eckert number in case of Dilatants fluids which are shown in Figure 24 and Figure 25. Tables 1-3 exhibit the behavior of $f^{\prime \prime}(0)$, $-\theta^{\prime}(0)$, and $-\varphi^{\prime}(0)$, for various values of magnetic parameter, stretching parameter, Prandtl number, Eckert number, Soret number, Casson parameter and Schmidt number. Here $f^{\prime \prime}(0)$ measures skin friction coefficient, that is, drag observed at the surface, whereas $-\theta^{\prime}(0)$ and $-\varphi^{\prime}(0)$ are measures of heat flux (rate of heat transfer) and mass flux (rate of mass transfer) at the surface, respectively. Also, when skin friction is positive, it means that the fluid exerts drag on the sheet; when negative, it means that the sheet exerts drag on the fluid. From Table 1, it is observed that $f^{\prime \prime}(0)$ is decreased for increasing values of $M$ and $n$ and increased for increasing values of $\lambda$. Therefore, with the increase in the magnetic parameter $M$, the skin friction decreases. As 
discussed above, the fluid velocity decreases due to an increase in magnetic parameter. For $M=0.30,0.35,0.40$ the sheet exerts drag on the fluid. Further, the decrease in fluid velocity with $M$ increases fluid temperature; therefore the rate of heat transfer decrease with an increase in $M$ which is shown in Table 2. From Table 2, it is observed that $-\theta^{\prime}(0)$, is increased with the increasing values of $M$ and $\operatorname{Pr}$ whereas reverse trend arises for $E c$. Since the rate of heat transfer is negative which means that the heat is transferred from fluid to sheet. From Table 3, we see that $-\varphi^{\prime}(0)$, is decreased with the increase of $M$ and increased for Sc, Ec and Pr.

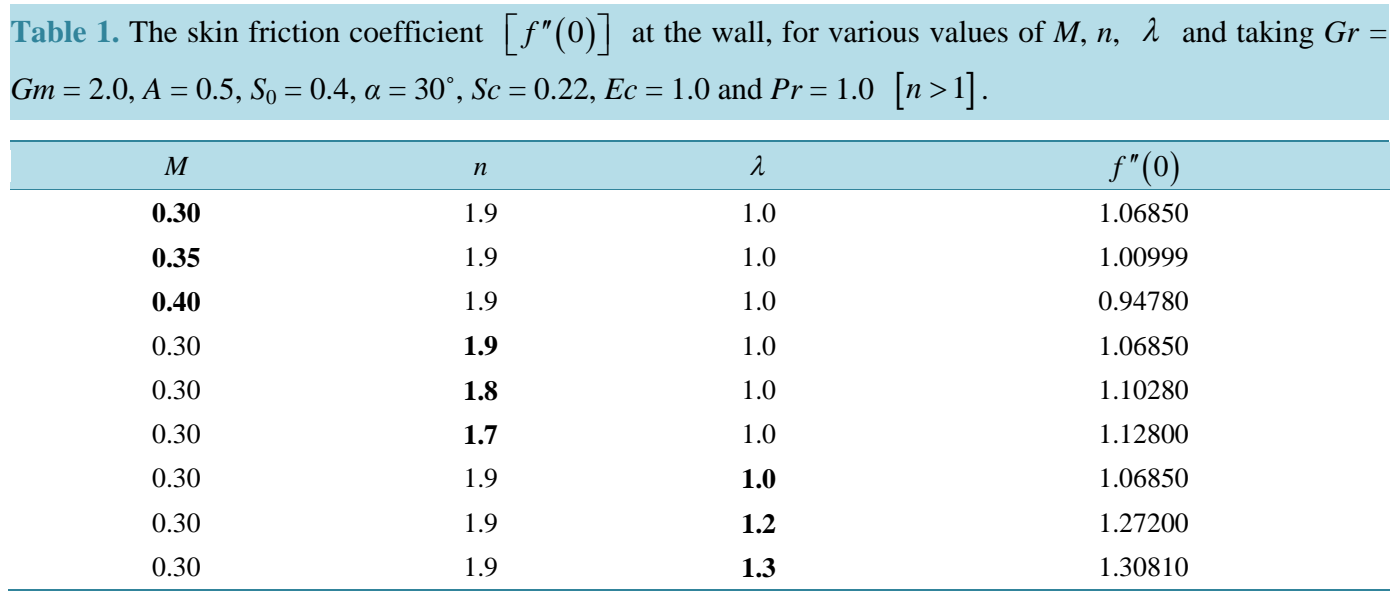

Table 2. The heat flux (rate of heat transfer) $\left[-\theta^{\prime}(0)\right]$ for various values of $M, P r, E c$ and taking $G r=G m$ $=2.0, A=0.5, S_{0}=0.4, \alpha=30^{\circ}, S c=0.22, \lambda=1.0$ and $n=1.9[n>1]$.

\begin{tabular}{cccc}
\hline$M$ & $P r$ & $E c$ & {$\left[-\theta^{\prime}(0)\right]$} \\
\hline $\mathbf{0 . 3 0}$ & 1.0 & 1.0 & 0.1660 \\
$\mathbf{0 . 3 5}$ & 1.0 & 1.0 & 0.1080 \\
$\mathbf{0 . 4 0}$ & 1.0 & 1.0 & 0.0495 \\
0.30 & $\mathbf{1 . 0}$ & 1.0 & 0.1660 \\
0.30 & $\mathbf{2 . 0}$ & 1.0 & 0.0910 \\
0.30 & $\mathbf{3 . 0}$ & 1.0 & 0.0003 \\
0.30 & 1.0 & $\mathbf{1 . 0}$ & 0.1660 \\
0.30 & 1.0 & $\mathbf{1 . 3}$ & 0.2574 \\
0.30 & 1.0 & $\mathbf{1 . 4}$ & 0.3318 \\
\hline
\end{tabular}

Table 3. The mass flux (rate of mass transfer) $\left[-\varphi^{\prime}(0)\right]$ for various values of $M, P r, E c, S c$ and taking $G r=$ $G m=2.0, A=0.5, \alpha=30^{\circ}, \lambda=1.0$ and $n=1.9[n>1]$.

\begin{tabular}{|c|c|c|c|c|}
\hline$M$ & $P r$ & $E c$ & Sc & {$\left[-\varphi^{\prime}(0)\right]$} \\
\hline 0.30 & 1.0 & 1.0 & 0.22 & 0.4377 \\
\hline 0.35 & 1.0 & 1.0 & 0.22 & 0.5028 \\
\hline 0.40 & 1.0 & 1.0 & 0.22 & 0.6079 \\
\hline 0.30 & 1.0 & 1.0 & 0.22 & 0.4377 \\
\hline 0.30 & 2.0 & 1.0 & 0.22 & 0.4130 \\
\hline 0.30 & 3.0 & 1.0 & 0.22 & 0.3510 \\
\hline 0.30 & 1.0 & 1.0 & 0.22 & 0.4377 \\
\hline 0.30 & 1.0 & 1.3 & 0.22 & 0.4042 \\
\hline 0.30 & 1.0 & 1.4 & 0.22 & 0.3721 \\
\hline 0.30 & 1.0 & 1.0 & 0.22 & 0.4377 \\
\hline 0.30 & 1.0 & 1.0 & 0.60 & 0.3610 \\
\hline 0.30 & 1.0 & 1.0 & 0.97 & 0.3350 \\
\hline
\end{tabular}




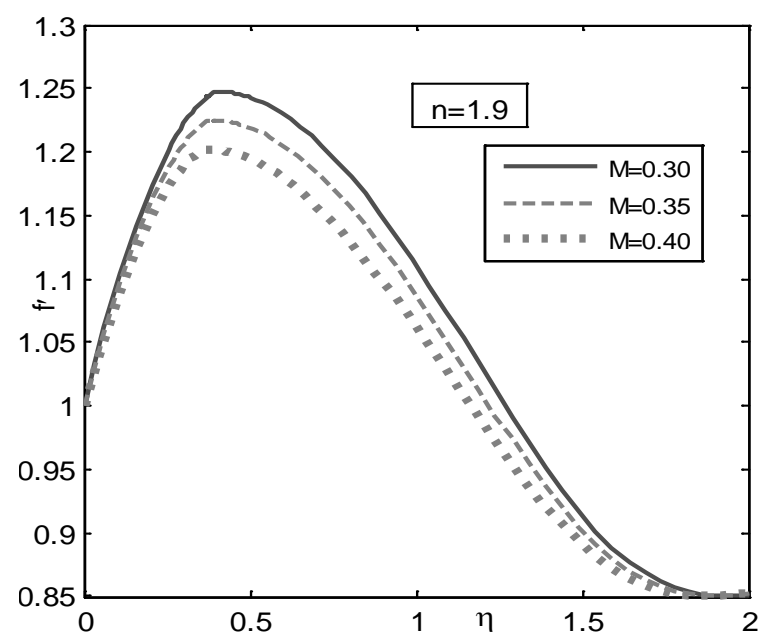

Figure 1. Velocity profile for various values of magnetic parameter.

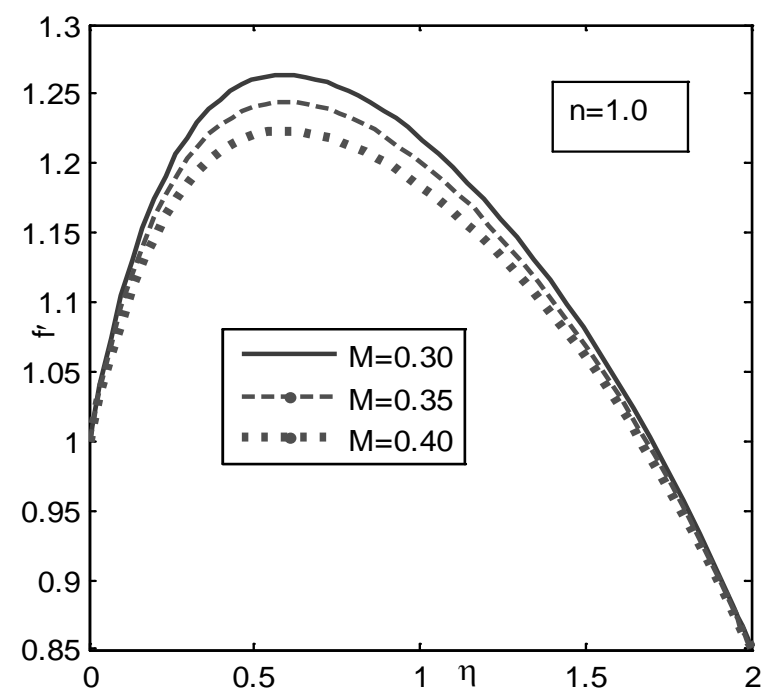

Figure 2. Velocity profile for various values of magnetic parameter.

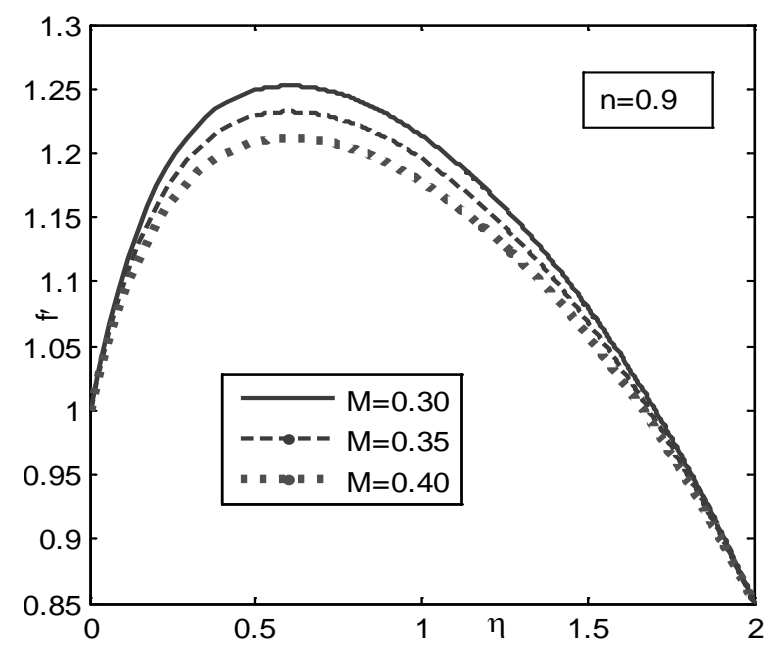

Figure 3. Velocity profile for various values of magnetic parameter. 


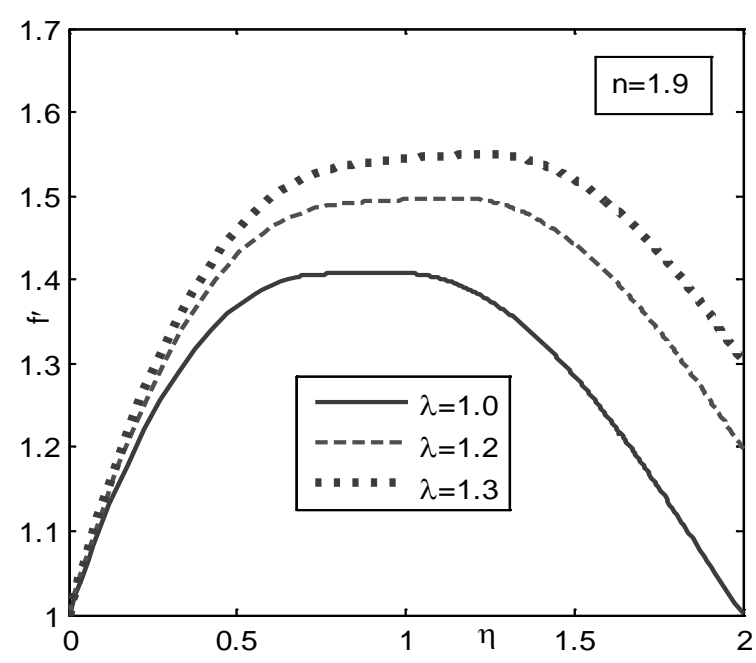

Figure 4. Velocity profile for various values of stretching ratio.

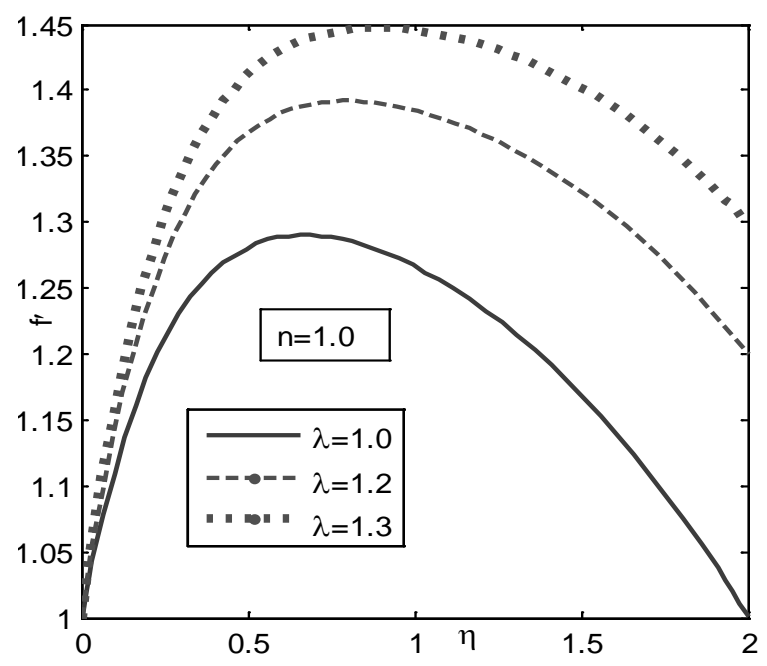

Figure 5. Velocity profile for various values of stretching ratio.

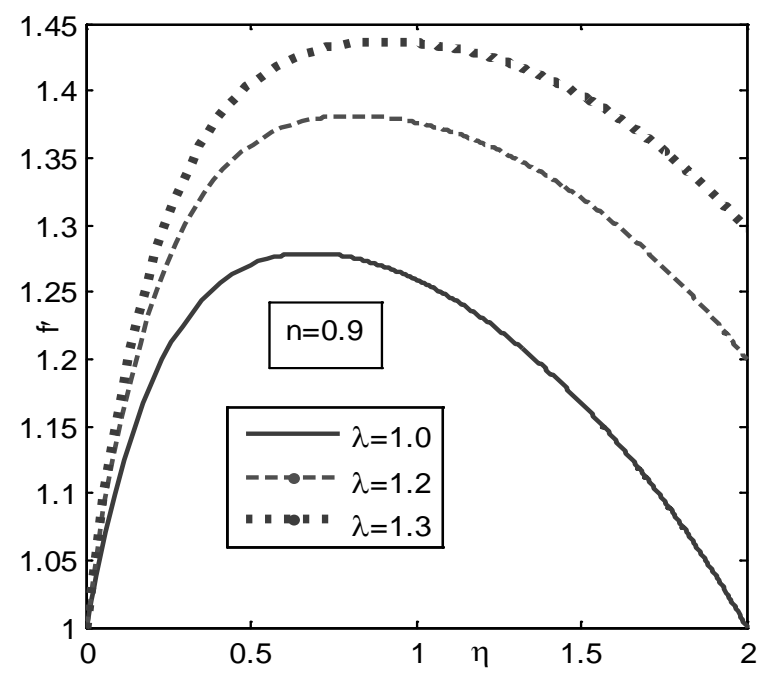

Figure 6. Velocity profile for various values of stretching ratio. 


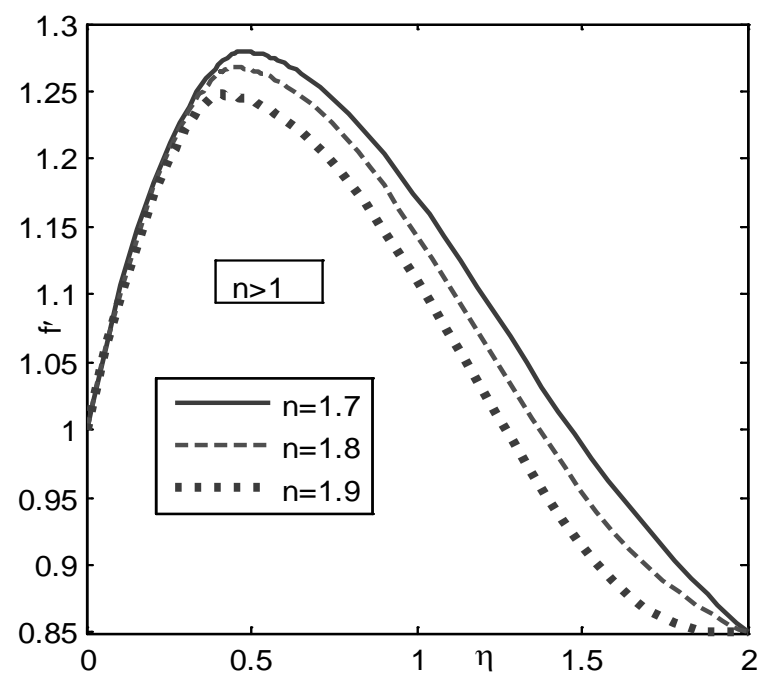

Figure 7. Velocity profile for various values of casson parameter.

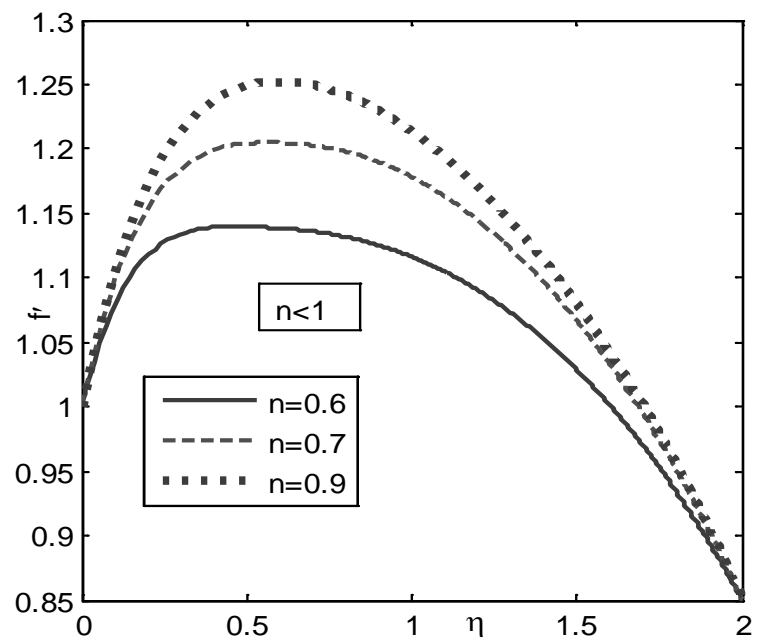

Figure 8. Velocity profile for various values of casson parameter.

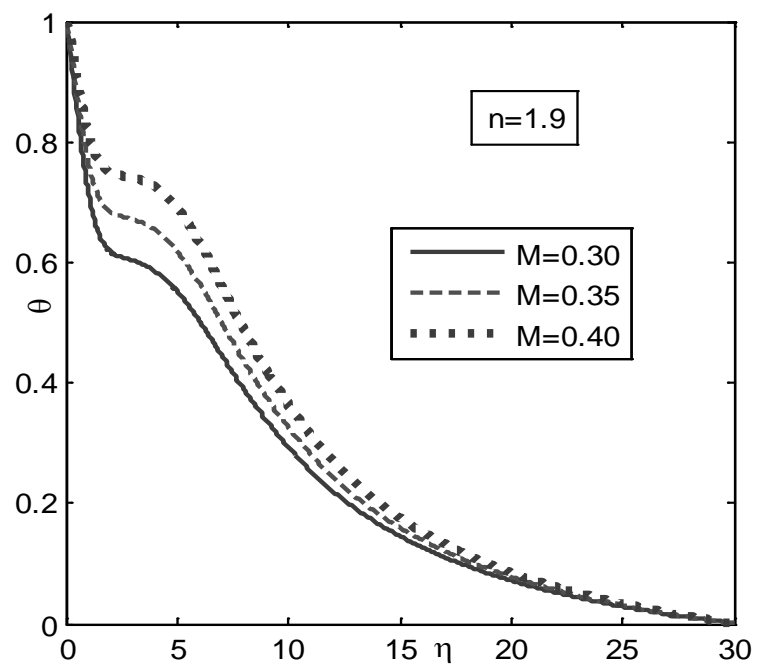

Figure 9. Temperature profile for various values of magnetic parameter. 


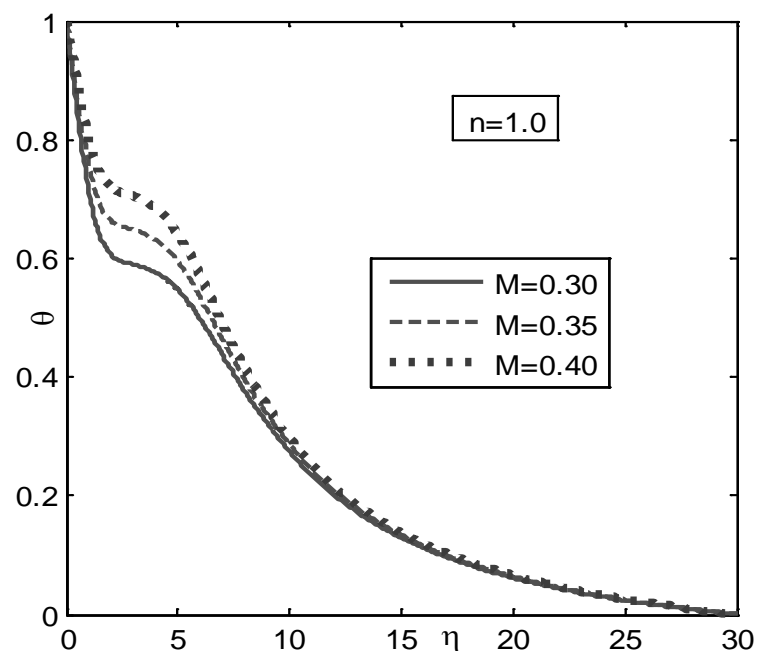

Figure 10. Temperature profile for various values of magnetic parameter.

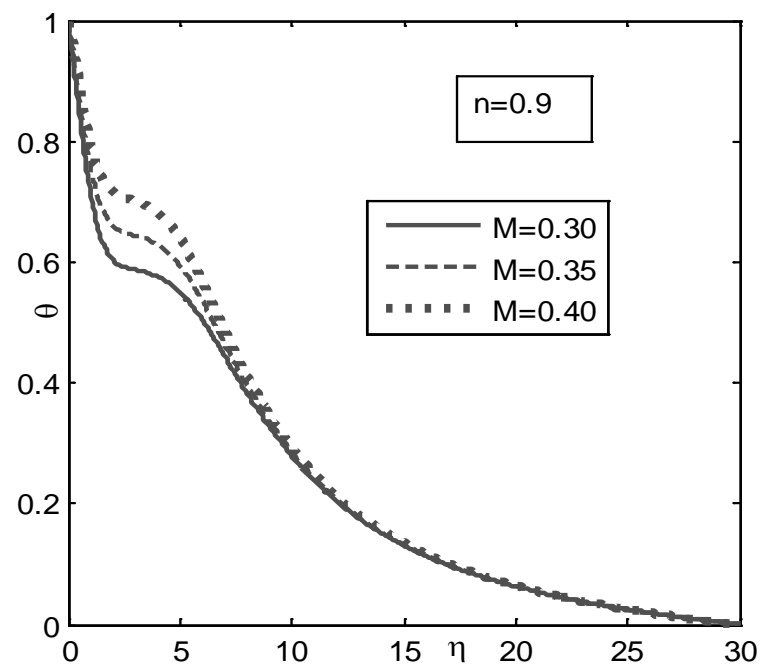

Figure 11. Temperature profile for various values of magnetic parameter.

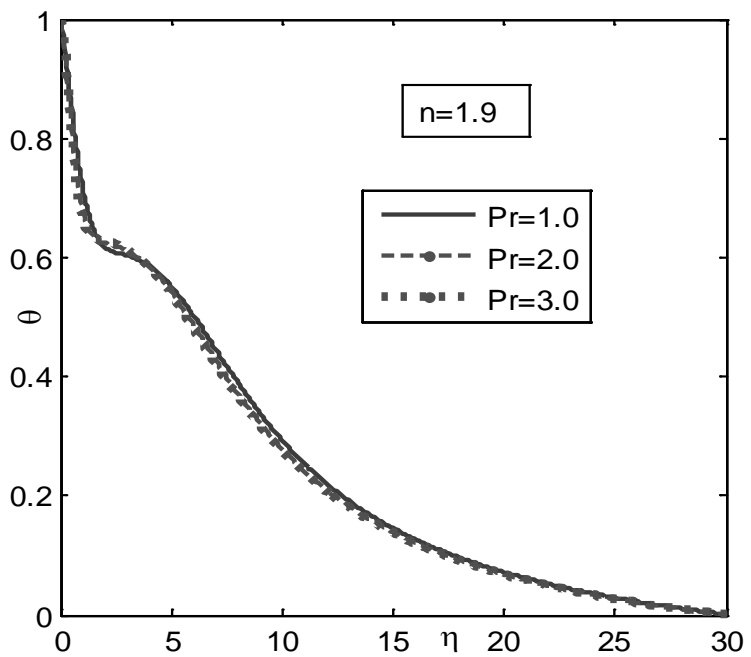

Figure 12. Temperature profile for various values of prandtl number. 


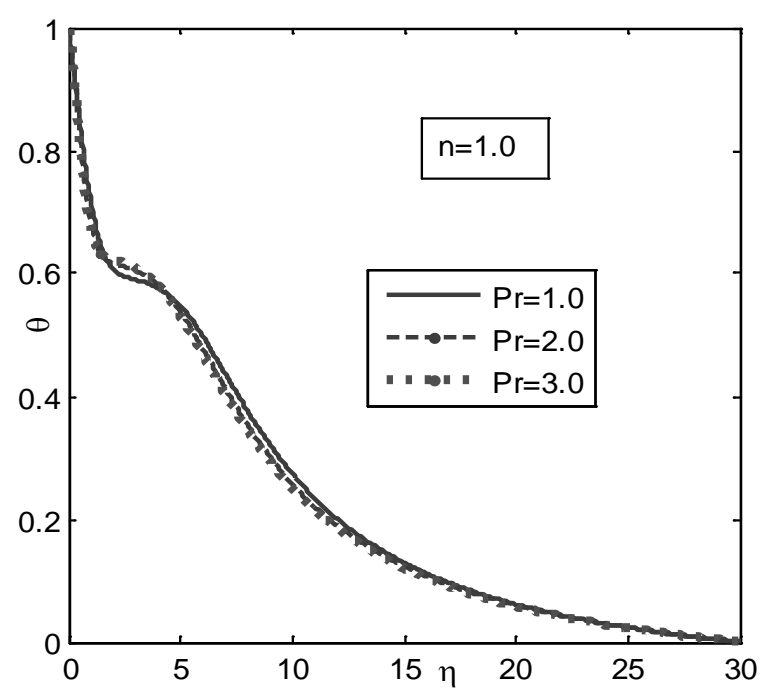

Figure 13. Temperature profile for various values of prandtl number.

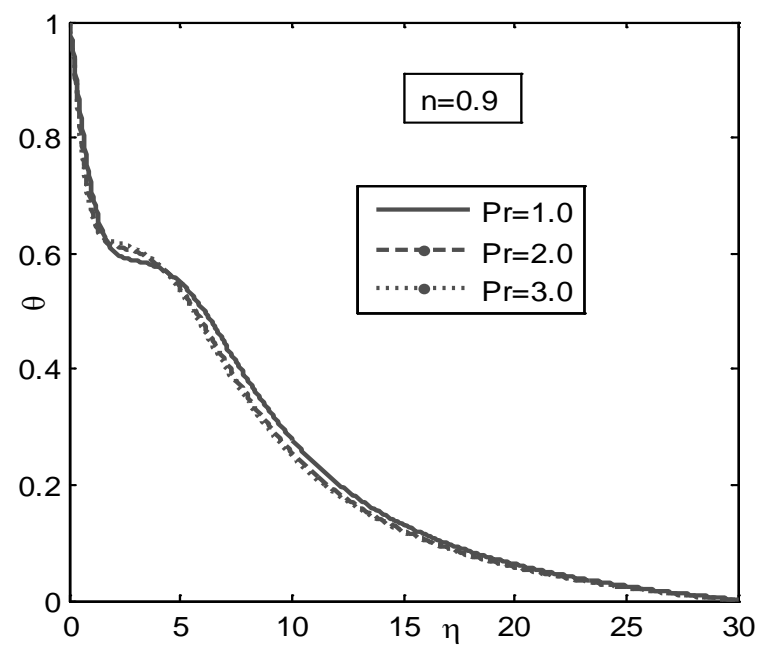

Figure 14. Temperature profile for various values of prandtl number.

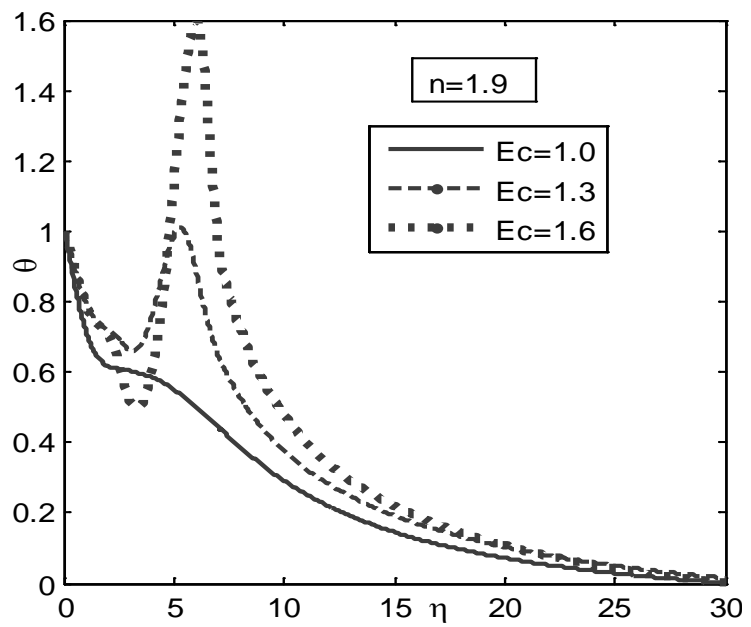

Figure 15. Temperature profile for various values of eckert number. 


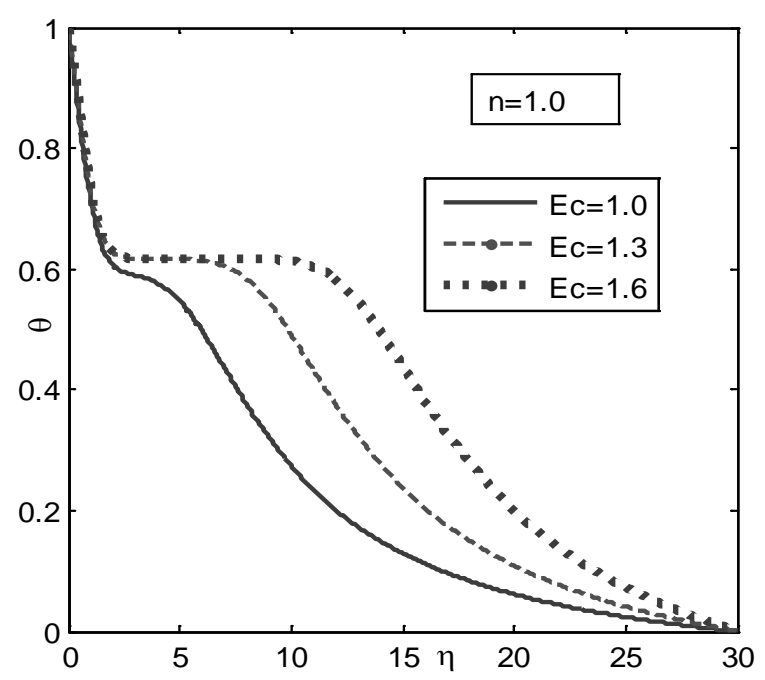

Figure 16. Temperature profile for various values of eckert number.

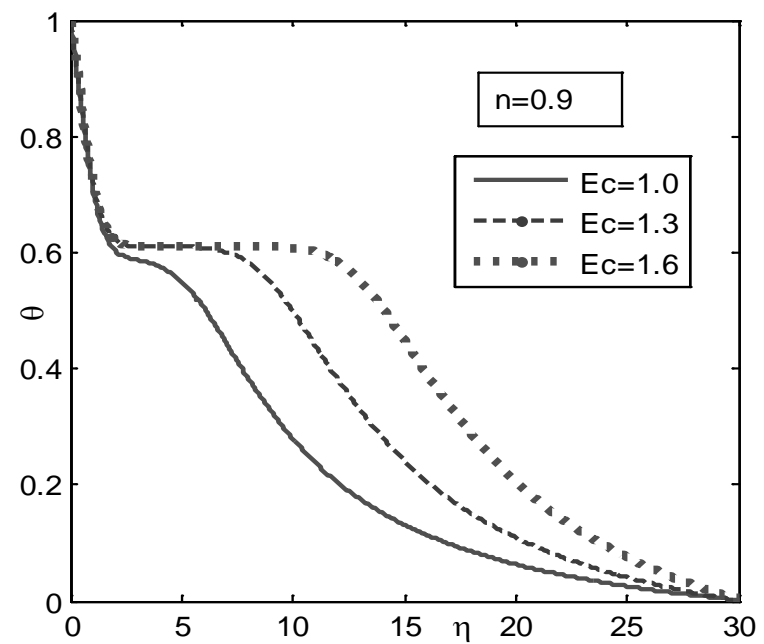

Figure 17. Temperature profile for various values of eckert number.

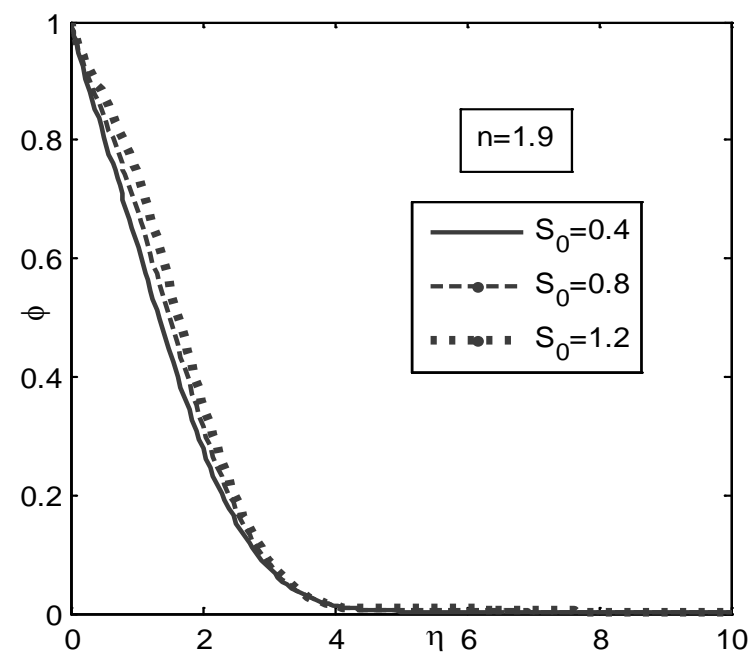

Figure 18. Concentration profile for various values of soret number. 


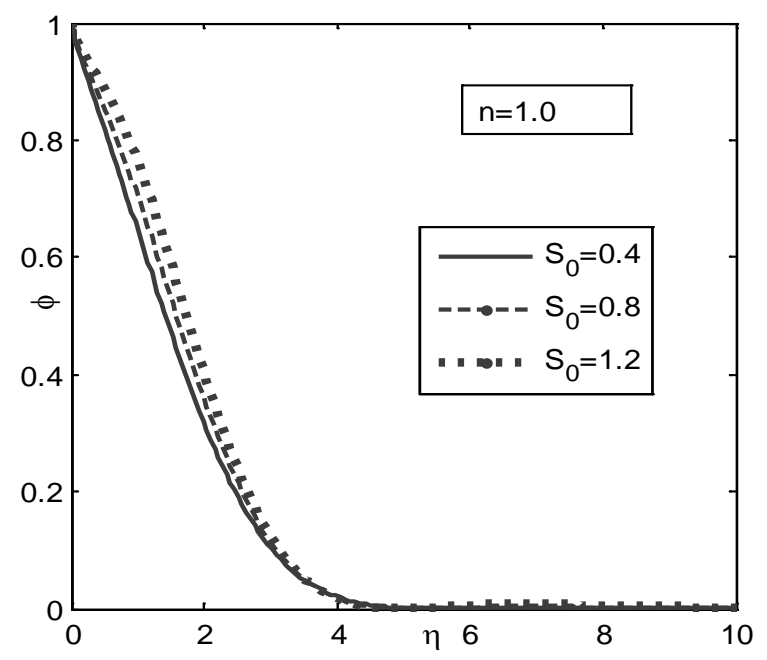

Figure 19. Concentration profile for various values of soret number.

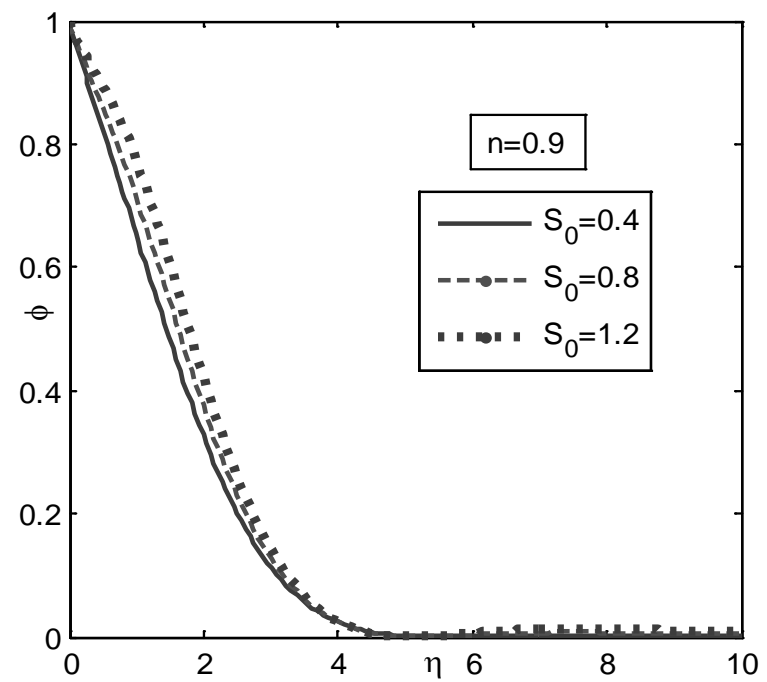

Figure 20. Concentration profile for various values of soret number.

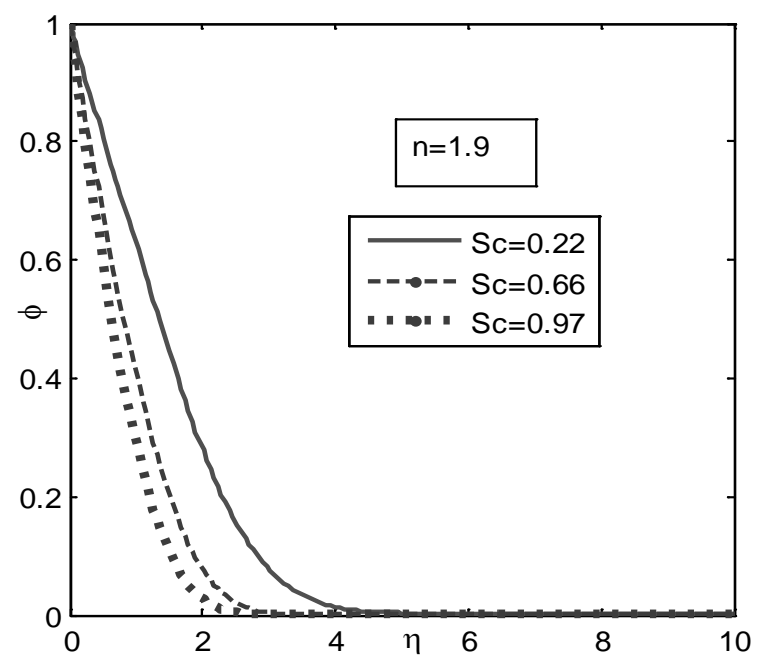

Figure 21. Concentration profile for various values of schmidt number. 


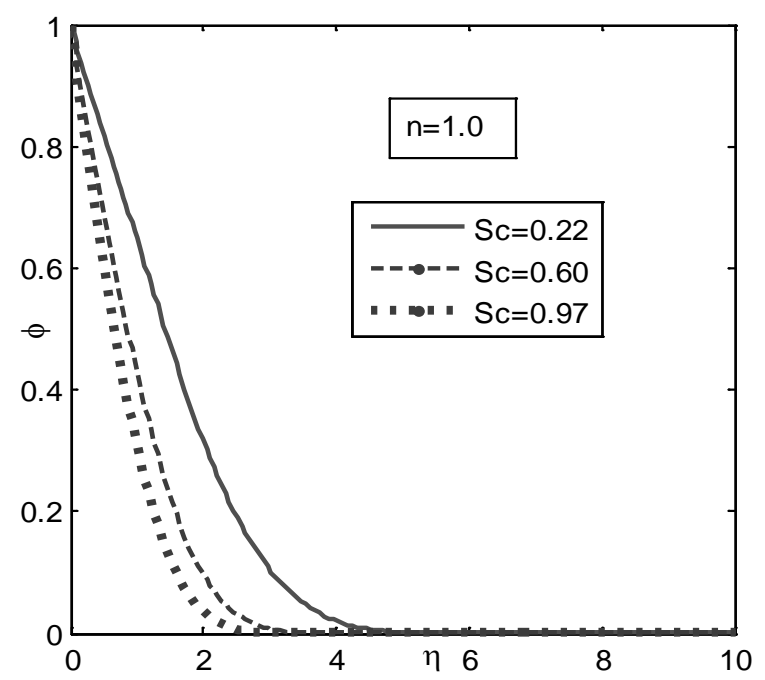

Figure 22. Concentration profile for various values of schmidt number.

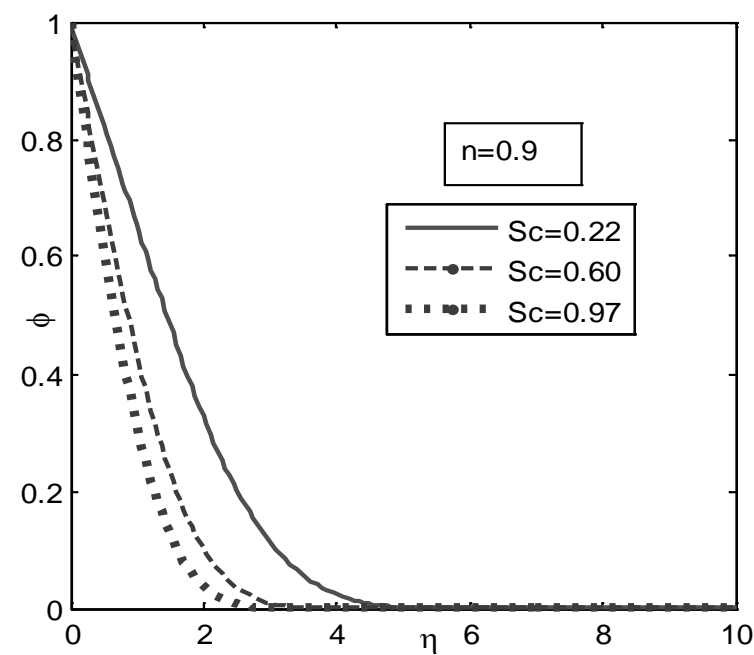

Figure 23. Concentration profile for various values of schmidt number.

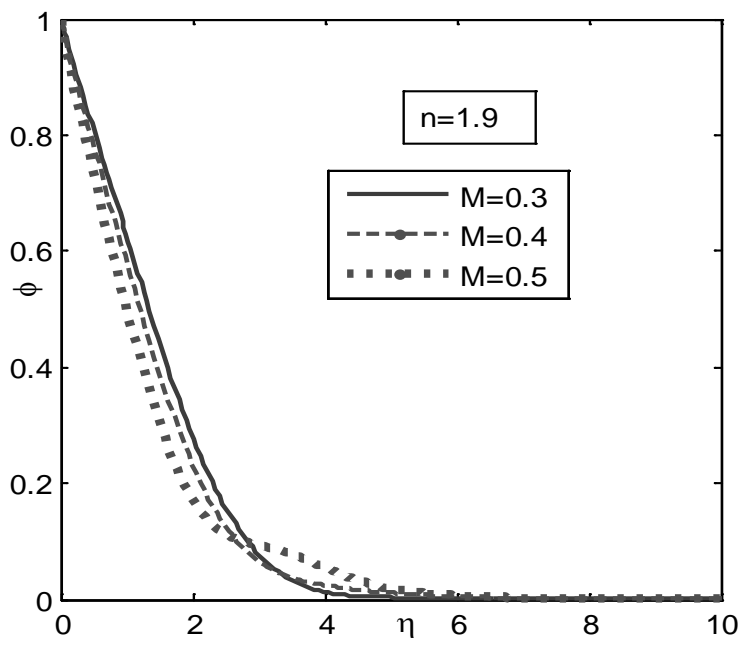

Figure 24. Concentration profile for various values of magnetic parameter. 


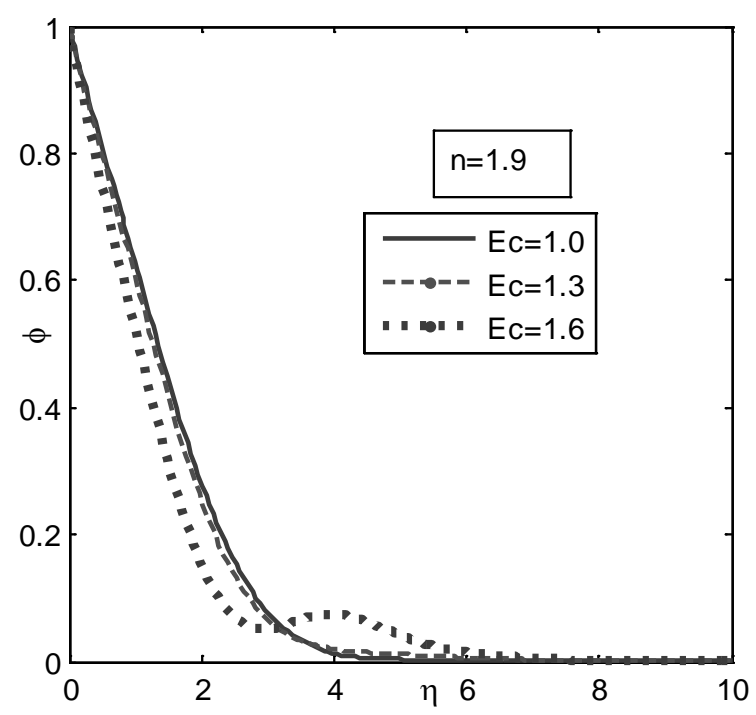

Figure 25. Concentration profile for various values of eckert number.

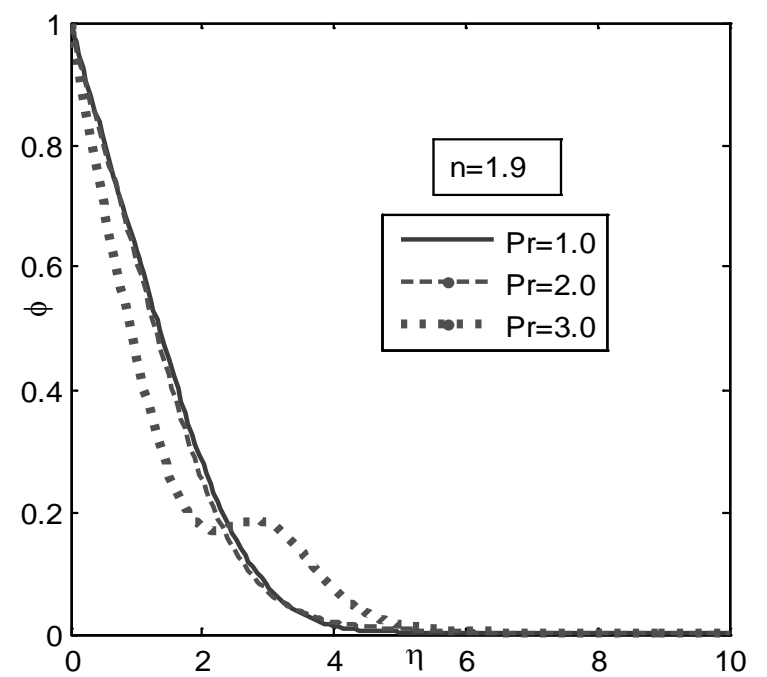

Figure 26. Concentration profile for various values of prandtl number.

\section{Conclusions}

The followings are conclusions made from the above analysis:

- The magnitude of velocity decreases with increasing magnetic parameter of Lorentz force for both Newtonian and non-Newtonian fluids but increases for the increasing values of stretching parameter $\lambda$.

- The thermal boundary layer increases for increasing values of magnetic parameter in both the cases of Newtonian and non-Newtonian fluids, meaning that the applied magnetic field in an electrical conducting fluid is manifested as thermal energy. Besides the fluid velocity decreases for magnetic parameter which leads to a decrease in heat convection and mass diffusion, and thus fluid temperature and species concentration in fluid increase. Similar results arises for the effect of Prandtl number Pr. Prandtl number is a property of fluids with small Prandtl number, and in general, it has high thermal diffusivity. Due to this property the fluid temperature is higher for a lower Prandtl number fluid and vice-versa. The increase in fluid temperature in turn increases the buoyancy force, so the fluid velocity increases. The increase in fluid velocity leads to better species diffusion; therefore, the species concentration decreases in the fluid, which is seen in Figure 26.

- A similar kind of interplay as above for Pr occurs for Schmidt number $S c$ and is seen in Figures 21-23. Schmidt number is a property of fluids that is a smaller value of $S c$, meaning better diffusion of species in 
fluid. Hence, for a small Schmidt number, the species concentration in the fluid is higher and vice versa for both Newtonian and non-Newtonian fluids. Similar result has been found for the increasing effect of magnetic parameter and Eckert number in case of Dilatants fluids which are shown in Figure 24 and Figure 25.

\section{References}

[1] Astarita, G. and Marrucci, G. (1974) Principles of Non-Newtonian Fluid Mechanic. McGraw-Hill, New York.

[2] Bohme, H. (1987) Non-Newtonian Fluid Mechanics. North-Holland Series in Applied Mathematics and Mechanics, North-Holland.

[3] Schowalter, W.R. (1960) The Application of Boundary Layer Theory to Power-Law Pseudo Plastic Fluid Similar Solutions. AIChE Journal, 6, 24-28. http://dx.doi.org/10.1002/aic.690060105

[4] Schowalter, W.R. (1978) Mechanics of Non-Newtonian Fluids. Pergamum Press, Oxford.

[5] Acrivos A., Shah, M.J. and Petersen, E.E. (1960) Momentum and Heat Transfer in Laminar Boundary Layer Flows of Non-Newtonian Fluids Past External Surfaces. AIChE Journal, 6, 312-317. http://dx.doi.org/10.1002/aic.690060227

[6] Mostafa, A.E.H.M. (2008) Slip Effects on Flow and Heat Transfer of a Non-Newtonian Fluid on a Stretching Surface with Thermal Radiation. International Journal of Chemical Reactor Engineering, 6, 1-20.

[7] Khan W.A. and Pop, I. (2010) Boundary-Layer Flow of a Nano Fluid past a Stretching Sheet. International Journal of Heat and Mass Transfer, 53, 2477-2483. http://dx.doi.org/10.1016/j.ijheatmasstransfer.2010.01.032

[8] Rana, P. and Bhargava, R. (2011) Numerical Study of Heat Transfer Enhancement in Mixed Convection Flow along a Vertical Plate with Heat Source/Sink Utilizing Nano Fluids. Communications in Nonlinear Science and Numerical Simulation, 16, 4318-4334. http://dx.doi.org/10.1016/j.cnsns.2011.03.014

[9] Rama, B. and Goyal, M. (2014) MHD Non-Newtonian Nano Fluid Flow over a Permeable Stretching Sheet with Heat Generation and Velocity Slip. International Journal of Mathematical, Computational, Physical and Quantum Engineering, 8, 910-916.

[10] Noghrehabadi, A., Pourrajab, R. and Ghalambaz, M. (2012) Effect of Partial Slip Boundary Condition on the Flow and Heat Transfer of Nano Fluids Past Stretching Sheet Prescribed Constant Wall Temperature. International Journal of Thermal Sciences, 54, 253-261. http://dx.doi.org/10.1016/j.ijthermalsci.2011.11.017

[11] Darji, R.M. and Timol, M.G. (2011) Deductive Group Theoretic Analysis for MHD Flow of a Sisko Fluid in a Porous Medium. International Journal of Applied Mathematics and Mechanics, 7, 49-58.

[12] Wilkinson, W.L. (1960) Non-Newtonian Fluids. Pergamum Press, New York. 